\title{
EDUCAÇÃO E REVOLUÇÃO NA AMÉRICA LATINA, O CASO DE CUBA: A HISTÓRIA QUE NÃO SE CONTA
}

\author{
Dayane de Freitas Colombo Rosa ${ }^{1}$, Roseli Gall do Amaral da Silva ${ }^{2}$, José Joaquim Pereira Melo ${ }^{3}$. \\ ${ }^{1}$ Universidade Estadual de Maringá - UEL, Programa de Pós Graduação em Educação, Maringá, PR. E-mail: \\ dayemarcio@hotmail.com. ${ }^{2}$ Universidade Tecnológica Federal do Paraná - UTFPR, Campus Apucarana-PR. E-mail: \\ amararoseli@gmail.com. ${ }^{3}$ Universidade Estadual de Maringá - UEM, Departamento de Fundamentos da Educação, \\ Maringá, PR. E-mail: pereirameloneto@hotmail.com
}

\section{RESUMO}

O objetivo desse artigo foi refletir sobre a história das revoluções latino americanas a fim de identificar os processos educativos e a construção da identidade latina. Para tanto, utilizou-se como procedimento metodológico a pesquisa bibliográfica em uma abordagem dialética, tendo a análise histórica como eixo norteador. Procurou-se responder as seguintes questões: Qual o conceito de América Latina? E qual a identidade Latino americano? E nesse sentido, identificar quais os processos educativos fruto da Revolução Cubana. A análise histórica possibilitou a compreensão de que se faz necessário fomentar o estudo da história da América Latina e o domínio do conhecimento de suas origens, no movimento concreto da história, justifica a identidade de um povo resistente, guerreiro que representa a unificação das diferenças.

Palavras-chave: América latina; História; Revolução; Educação.

\section{EDUCATION AND REVOLUTION IN LATIN AMERICA, THE CASE OF CUBA: THE HISTORY NOT ACCOUNTED}

\begin{abstract}
The purpose of this article was to reflect on the history of the Latin American revolutions in order to identify the educational processes and the construction of the Latin identity. For this purpose, the bibliographic research was used as a methodological procedure in a dialectical approach, with historical analysis as the guiding axis. We sought to answer the following questions: What is Latin America? What is it to be Latin American? What are the educational processes resulting from the Revolutions? Historical analysis made it possible to understand that it is necessary to foster the study of Latin American history and the domain of knowledge of our origins, for the concrete movement of history to which we are part justifies in itself our identity as a resilient, warlike people which represents the unification of differences.
\end{abstract}

Keywords: Latin America; History; Revolution; Education. 


\section{INTRODUÇÃO}

A História da educação e revoluções latino americanas é um tema que tem sido alvo de discussões teóricas no ramo das ciências humanas que problematizam e compreendem esse fenômeno como um todo indissociável as questões econômicas, políticas, sociais e culturais imbricado numa relação dialética complexa, porém pouco ensinado ao povo latino.

É comum na maioria das escolas ensinar história a partir de uma perspectiva eurocêntrica, enfatizando os "heróis" e as datas das conquistas fundamentais que ocorreram no mundo. Fazendo-nos desconhecer nossas origens Astecas, Incas e Maias ${ }^{1}$ e buscar nos europeus nossa identidade.

Assim, ao desconhecer nossas origens e assumir como nossa as origens europeias pode ser um dos fatores que contribuiu para que a discussão sobre a aceitação e consolidação do nome "América Latina" percorresse um período de quase dois séculos e também para que o povo latino americano até hoje seja considerado pelos europeus um povo periférico e inferior, pois um povo sem identidade é facilmente dominado. Para Arturo Ardao (1978) "no saber cómo llamarse es algo más que no saber cómo se es; es no saber quién se es" (ARDAO, 1978, p.22).

Essas constatações e as discussões realizadas em sala de aula na disciplina "Revoluções e Educação na América Latina", no segundo semestre do ano de 2017 do Programa de Pós Graduação em Mestrado em Educação da Universidade Estadual de Maringá/ UEM, justifica a escolha do objeto de pesquisa deste trabalho. O objetivo geral foi refletir sobre a história da revolução cubana a fim de identificar os processos educativos constituídos que contribuem para a construção da identidade latina.

\section{RESULTADOS}

$\mathrm{Na}$ atualidade, o termo América Latina, em parte, é utilizado para referenciar os habitantes que vivem abaixo do Rio Grande ${ }^{2}$, faz parte dessa região 12 países da América do Sul, 14 do caribe e 07 da América Central totalizando aproximadamente 700 milhões de habitantes (ARAÚJO, 2006).

Ao fazer uso do termo América Latina compreende-se que esse conceito envolve discussões que vão do âmbito da linguística até a biologia e que devido a sua pluralidade ainda não está totalmente definido, para Diniz (2007), o conceito de América Latina é visto como problemático.

Durante muito tempo o conceito "América Latina" foi sinônimo de subdesenvolvidos, não civilizados, povo pobre, nativo e corrupto. Este cenário começa a mudar a partir das décadas de 1950-1960, quando os Estados Unidos da América a fim de impor uma maior dominação atribui a essa expressão diversos discursos políticos e ideológicos.

Dessa forma, o conceito América Latina nasce num sentido ideológico e pejorativo, como adjetivo e não substantivo. Atualmente, alguns estudiosos, entendem por América latina os países de língua espanhola, portuguesa e francesa, porém, a conceituação de um povo não se dá somente pela língua materna e sim por sua aculturação, dessa forma a língua nacional é apenas um fator determinante da identidade latina, mas não o fator principal.

Corrobora-se com a ideia de que a identidade de um povo passa pela politização do indivíduo, ou seja, "requer a identificação do indivíduo com uma coletividade mais ampla" (FLEURY, 1994, p.113), sendo sua condição política fundamental. Destarte, as possibilidades para a desconstrução negativa do conceito América latina, portanto de superação da coletividade inferiorizada, são retomar as nossas origens, ou seja, conhecer nossa história e politizar a educação.

\footnotetext{
${ }^{1}$ Foram povos que dominaram as Américas antes da chegada dos europeus no século XVI e que apresentavam um grau elevado de desenvolvimento cultural, eram organizados em estados e comandados por um complexo sistema religioso.

${ }^{2}$ Fronteira do México e Estados Unidos.
} 
Dessa forma, o processo histórico que produziu a revolução do México, Bolívia, Cuba e Nicarágua, não será compreendido ao enfatizar os "heróis" e as datas das conquistas fundamentais que ocorreram na América Latina, ignorando o que existia antes, todavia a teoria adotada exige que tenhamos como ponto de partida o estudo da forma como os homens se organizavam no período de cada revolução para a manutenção da vida, pois entende-se que cabe ao pesquisador da área de história e historiografia da educação "Adotar estratégias para ultrapassar a materialidade dos fatos, para chegar à sua "intencionalidade", ao seu sentido. Mantendo-os integrados ao seu âmbito histórico, põem-se à luz seus antecedentes, sequências ou repercussões" (PEREIRA MELO, 2010, p.18-19), Para Ailton Souza em seu texto "América Latina, conceito e identidade: algumas reflexões da história" de 2011, a identidade de um povo se consolida pelo reconhecimento de sua cultura. Porém, por ser uma região com várias particularidades e diferenças culturais, essa porção geográfica foi vista "sob o olhar do "outro" ou da visão euro centrista colonialista a partir de concepções negativas relacionadas às suas características expressivas de pobreza e corrupção eram vistas como inseparáveis do indivíduo latino" (SOUZA, 2011, p. 7).

Castells (1996), compreende que "a construção de identidades vale-se de matéria-prima fornecida pela história, geografia, biologia, instituições produtivas e reprodutivas, pela memória coletiva e por fantasias pessoais, pelos aparatos de poder e revelações de cunho religioso" (p. 23).

Dessa forma, destaca-se a importância do historiador para a construção da identidade de um povo. Sendo assim, Souza $(2011$, p. 7) explicita que a identidade latino americana "era deturpada por teorias e ideologias dominantes". O autor salienta que o "povo latino também seria obrigado a compreender a sua realidade a partir de parâmetros importados e impostos" (SOUZA, 2011, p. 8), o que contribui para a auto rejeição de quem somos, pois muitos latinos não se reconhecem como tal.

Assim, o povo latino não apresenta uma identidade definida, pois não detém o conhecimento de quem é, não possui o conhecimento real de sua história, marcada por lutas e entraves que o caracteriza como povo guerreiro, forte, resistente e perseverante. A educação na maioria das vezes foi utilizada nos movimentos revolucionários da América Latina como um instrumento de luta para a consolidação de uma identidade própria, latino-americana, como foi o caso da Revolução cubana.

\section{METODOLOGIA}

O artigo foi estruturado por um caráter bibliográfico, utilizou-se como referência de leitura autores que possibilitam maior entendimento sobre o conceito de América Latina e o processo educativo em Cuba, tais como: Ardao (1978), Souza (2011), Hobsbawn (1995), Blanco e Dória (1982) e Huteau e Lautrey (1976), fundamentando-se no princípio de que a identidade de um povo é construída socialmente, de forma dialética, a partir da materialidade em que vivem.

\section{DISCUSSÃO}

Uma das características do povo latino é a resistência. A história revela que a América Latina foi foco de resistências e, um dos movimentos que expressam essa peculiaridade é a Revolução Cubana. A República de Cuba é um país que está localizado na América Central, entre o Golfo do México e o mar do Caribe, tendo como capital a cidade de Havana e aproximadamente 11 milhões de habitantes. Cuba em 1959 tinha como cenário uma condição precária no ensino com alto índice de analfabetismo e falta de professores, porém, desenvolveu uma trajetória que tratou a educação como prioridade para consolidar o processo revolucionário e atualmente tem a mostrar aos outros países da América Latina indicadores de "[...] superação do analfabetismo, ampla escolarização e organização de instituições de pesquisa de ponta [...]" (SEGRERA, 2012, p. 17). 
Cuba foi colônia espanhola de 1510 a 1898 e sua independência não foi conquistada como por outras ex-colônias no período das guerras napoleônicas e sim por intervenção militar dos EUA no início do século XX, o que faz com que ao deixar de ser colônia espanhola a pequena ilha tornase neocolônia americana. Por razões econômicas, com o intuito de expandir território do Oeste ao Sul e com medo do predomínio britânico, desde que se tornou independente, em 1783, os Estados Unidos cobiçou o território cubano. Thomas Jefferson (1743-1826) foi o terceiro presidente dos Estados Unidos e declarou em 1823 que "a anexação de Cuba seria a melhor maneira de promover o poderio norte - americano até o limite máximo de seu interesse" (BLANCO; DÓRIA, 1982, p.12).

A circunstância conveniente para que a intervenção militar acontecesse foi o bombardeio ao norte-americano Maine ancorado na cidade de Havana no dia 15 de fevereiro de 1898 que resultou em 260 homens vitimados, os EUA responsabilizaram os espanhóis pela explosão e decidiram que Cuba deveria ser livre e soberana declarando guerra à Espanha no dia 23 do mesmo mês. A guerra finaliza-se com a assinatura espanhola do Tratado de Paris reconhecendo a independência cubana. A partir de então Cuba é ocupada pelos militares norte-americanos comandados pelo general Leonardo Wood (1860-1927). Após a ocupação o senador norteamericano Orville Hitchcock Platt (1827-1905) apresenta a Emenda Platt que é anexada a Constituição da ilha em 1901, fazendo com que a nação agora considerada independente se sujeitasse ao imperialismo estadunidense.

A intenção de americanizar Cuba não ficou apenas sobre a indústria açucareira, nesse período acontecem modificações na agricultura, na produção do tabaco, mineração, transportes, geração de energia e após a queda em 1920 dos preços do açúcar também no sistema bancário. Destarte, a economia de Cuba foi se caracterizando como uma espécie de "economia de sobremesa - produtora de açúcar, tabaco, licores e frutas - a tal ponto que, até 1915, Cuba não possuiu sequer moeda própria" (BLANCO; DÓRIA, 1982, p.22). Por consequência Cuba se torna do ponto de vista econômico dependente dos Estados Unidos, e o sonho da independência se evapora, soterrando os ideais propostos por José Martí ${ }^{3}$.

Depois de aproximadas cinco décadas e do governo de ditadores como Gerardo Machado y Morales (1871-1939) e de Fulgencio Batista (1901-1973), desenvolveu-se em Cuba um cenário de miséria, educação e saúde deficiente. Mediante a insatisfação popular, em 1953 com o assalto ao quartel Moncada inicia-se a Revolução que foi liderada por Fidel Castro e Che Guevara. Segundo o autor Hobsbawn, (1995), a saga de Fidel Castro, Che Guevara e seus guerrilheiros só realizaram a revolução porque o:

[...] regime de Batista era frágil, não tinha apoio real, a não ser o motivado pela conveniência e o interesse próprio, e era liderado por um homem tornado indolente por longa corrupção. Desmoronou assim que a oposição de todas as classes políticas, da burguesia democrática aos comunistas, se uniram contra ele, e os próprios agentes, soldados, policiais e torturadores do ditador concluíram que o tempo dele se esgotara (HOBSBAWN, 1995, p. 426).

Após a conquista do poder pelos revolucionários desenvolver uma consciência revolucionária tornou-se prioridade e a educação foi utilizada como um dos pilares fundamentais para atingir esse objetivo, o primeiro passo para isso foi a Campanha de Alfabetização.

Quando o exército rebelde conquista o poder, a primeira ação a ser tomada foi a criação da Comissão Nacional de Alfabetização e Educação Fundamental. E em 1961 é realiza uma intensiva campanha contra o analfabetismo no país, pois esse fenômeno era considerado pelos dirigentes

\footnotetext{
3José Martí (1853-1895) político que participou da fundação do partido Revolucionário Cubano, é conhecido como referência, leia-se herói, no processo de luta pela independência cubana, todavia defendia ideais da fisiocracia americana ancorado no teórico Henry George (1830-1897). Defendia a formação do homem cidadão a partir de princípios burgueses. Muitos fazem de Martí um herói, outros um traidor da sua causa, pois dizem que não assumiu a sua identidade Latino Americana ao defender para a sociedade cubana princípios que contribuíram para a manutenção das desigualdades já existentes.
} 
da revolução um inimigo tão poderoso quanto o imperialismo estadunidense. A campanha de alfabetização não fora o objetivo final para a consolidação de uma educação revolucionária, mas a primeira etapa desse processo (HUTEAU; LAUTREY, 1976).

A comissão organizou um curso acelerado de quinze dias para capacitar mestres voluntários para ensinar os adultos, essa iniciativa foi divulgada pela televisão, pelos discursos de Fidel. Foi necessário realizar uma investigação para saber qual seria o método mais apropriado para ensinar os adultos camponeses, pois, deveriam expressar uma linguagem e um conteúdo ideológico que elucidasse os problemas específicos do momento, por isso, se pensou em criar um livro, uma cartilha revolucionária. Organizou-se para tanto, uma investigação com a participação de 3000 pessoas maiores de 16 anos que foram enviados as regiões montanhosas para conhecer a linguagem dos analfabetos, sua concepção de mundo, sua realidade econômica e social.

Após quatro meses de investigação foram publicados a cartilha Venceremos e o manual do professor Alfabetizemos. A cartilha de alfabetização é composta de 15 lições e o manual apresenta 24 temas de orientação revolucionária que expõe os objetivos da revolução cubana e as dificuldades que enfrentarão para que a mesma se consolide. O manual foi criado com o objetivo de politizar os professores voluntários e de direcioná-los com relação ao foco que deveria ser dado às discussões dos temas da cartilha. A campanha apresentou como slogan o seguinte tema: "que todo analfabeto tenha um alfabetizador - que todo alfabetizador tenha um analfabeto! [...] Se não sabes aprende; se sabes, ensina!" (HUTEAU; LAUTREY, 1976, p. 37).

A campanha permitiu que a revolução que estava ameaçada pelo bloqueio econômico se consolidasse e fortalecesse em todo o país, permitiu que todo um povo recuperasse a sua dignidade, isso só foi possível porque as condições materiais eram favoráveis como por exemplo a unidade da língua, o engajamento da população e aos fatores políticos. (HUETAU; LAUTREY, 1976). Pode-se dizer que a campanha de alfabetização foi a primeira etapa para a construção do projeto antropológico cubano - o homem novo.

Pode-se considerar que a grande catarse do movimento revolucionário cubano foi fazer com que todo guerrilheiro fosse ao mesmo tempo mestre, conscientizando a população camponesa sobre os ideias revolucionárias e a necessidade da construção de uma nova moral e uma nova forma de trabalho: o trabalho produtivo e voluntário.

Desse modo, a educação em Cuba, além de ser um processo escolar, adquiriu características próprias de formação social, pois cada cubano deveria ser um propagador de cultura, que se autolibertou, e ainda, motiva outros a se libertarem.

\section{CONCLUSÃO}

Os princípios aqui discutidos nos levaram a problematizar que a América Latina é uma região marcada por um povo sofrido e explorado, que por falta de conhecimento de sua história não reconhece o seu valor, e mascara sua dignidade. Dito de outra forma, evidencia-se o que foi explícito por Roberto Reis em "O espaço da latino-Americanidade, Crítica Literária Latino Americana" de 1988 que "enquanto a América Latina não assumiu (não assume) a condição de seu processo histórico, a realidade em vigência entre nós foi (tem sido) a europeia" (REIS, 1988, p. 26).

Os movimentos sociais, ou seja, as revoluções latino americanas, elucidam que ser latino americano é ser guerreiro, e que quando compreendem a força que tem faz o uso dos diversos meios para resgatar sua dignidade, deixando de ser objeto e para ser sujeito de sua história (REIS, 1988).

A educação na maioria das vezes é utilizada para testificar a vontade de um povo sofrido e marginalizado em instituir valores e modificar a relação entre os homens, como podemos observar na Revolução de Cuba.

Desse modo, faz-se necessário despertar no homem latino americano a identidade de uma nação rica em cultura e língua, para que possa enxergar-se como a unificação dos diferentes. Para 
que isso possa acontecer, como já dizia Marx e Engels (1986), "dominar o que os dominantes dominam" (MARX; ENGELS, 1986, p.56), ou seja, o conhecimento, a ciência, em outras palavras a própria história.

\section{REFERÊNCIAS}

ARAÚJO, Maria. C. Prospectos da democracia na América Latina em 2006. Rio de Janeiro: CPDOC/FGV, 2006, p.1-13.

ARDAO, Arturo. La idea de la magna Colombia de Miranda a Hostos. Centro de Estudios Latinoamericanos, Facultad de Filosofía y Letras, Coordinación de Humanidades, Universidad Nacional Autónoma de México, UDUAL, 1978.

BLANCO, Abelardo; DÓRIA, Carlos A. Revolução Cubana: de José Martí a Fidel Castro (1868 1859). 2. Ed. São Paulo: Brasiliense, 1982.

CASTELLS, Manuel. O poder da identidade, v. II, Paz e Terra, São Paulo, 1996, p. 22 -28.

DINIZ, Dilma Castelo Branco. O conceito de América Latina: uma visão francesa. Caligrama, Belo Horizonte, v. 12, p. 129-148, 2007.

FLEURY, Sonia. Estado sem cidadãos: seguridade social na América Latina. FIOCRUZ, 1994.

HOBSBAWM, Eric J. Era dos Extremos: O breve século XX: 1914-1991. 2 ed. São Paulo: Companhia das Letras, 1995.

HUTEAU, Michel; LAUTREY, Jacques. Cuba: revolução no ensino. Trad. De Manuela Leandro e Fernanda Campos. Coimbra: Centelha, 1976.

MARX, Karl; ENGELS, Friedrich. A ideologia alemã (Feuerbach). 5. ed. Tradução de José Carlos Bruni e Marco Aurélio Nogueira. São Paulo: Hucitec, 1986. p.15-77.

PEREIRA MELO, José Joaquim. Fontes e Métodos: sua importância na descoberta das heranças educacionais. In: COSTA, Célio Juvenal; PEREIRA MELO, Joaquim José; FABIANO, Luiz Hermenegildo (Org). Fontes e métodos em história da educação. Dourados, MS: Ed.UFGD, 2010. p. 13 - 35.

REIS, Roberto. O espaço da latino-Americanidade, Crítica Literária Latino Americana, Lima, 1988, p.25-37.

SEGRERA, Francisco López. A Revolução Cubana: propostas, cenários e alternativas. Tradução Mário Luiz Neves de Azevedo, Gilda Teresa Contreras López. Maringá: Eduem, 2012.

SOUZA, Ailton. América Latina, conceito e identidade: algumas reflexões da história. PRACS: Revista de Humanidades do Curso de Ciências Sociais da UNIFAP, Macapá, n. 4, p. 29-39, dez. 2011. 